\title{
A ocupação do espaço e a transformação do território: um estudo sobre a posse de terras em Sant'Ana de Paranaíba (MT) no século XIX
}

\author{
The occupation of space and the transformation of the territory: a study on land \\ possession in Sant'Ana de Paranaiba (MT) in the nineteenth century
}

La ocupación del espacio y la transformación del territorio: un estudio sobre la tenencia de la tierra en Sant'Ana de Paranaiba (MT) en el siglo XIX

Isabel Camilo de Camargo*

Ricardo Lopes Batista*

\section{Resumo}

O presente artigo tem como objetivo discutir a posse de terras em Sant'Ana de Paranaíba no século XIX, a partir de inventários post mortem e contratos de compra e venda; documentos existentes no Arquivo do Tribunal de Justiça de Mato Grosso do Sul sediado em Campo Grande. O texto se articula com os conceitos geográficos de espaço e território para melhor compreender a ocupação dessa localidade. $\mathrm{Na}$ análise espacial, reconhecemos que as características espaciais foram consideradas no processo de escolha das propriedades, sendo as áreas localizadas próximas aos recursos hídricos, demonstrando que o espaço não é apenas o local onde as interações sociais ocorrem, é mais do que isso, ele é, ao mesmo tempo, determinante e possibilitador de novas relações.

Palavras-chave: Análise espacial. Ocupação. Sant' Ana de Paranaíba.

Doutora em História pela Unesp/Assis (2015), com bolsa sanduíche Capes/PDSE na Universidade de Coimbra, Portugal. Professora da Universidade Federal de Mato Grosso do Sul, Brasil. E-mail: isabelc_camargo@hotmail.com

** Doutor em Geografia pela Universidade Estadual Paulista com doutorado sanduíche na Universidade de Coimbra, Portugal. Professor do Programa de Pós-Graduação em Geografia da Universidade Federal de Mato Grosso do Sul, Brasil. E-mail: batista-lopes@hotmail.com

Recebido em 20/02/2017 - Aprovado em 12/04/2017 http://dx.doi.org/10.5335/hdtv.17n.2.5909 


\section{Introdução}

Após a criação da capitania de Mato Grosso (1748), iniciou-se uma preocupação com a ocupação desse território. Nas fronteiras com o império espanhol, era necessária a presença de soldados, porém, as localidades que não faziam divisa estavam abertas a outras formas de fixação.

É importante ressaltar que, naquela época, sobressaía a ideia de "vazio", na qual os dominadores não enxergavam os indígenas como habitantes de determinada localidade, já que a fixação territorial deveria ser realizada por europeus ou seus descendentes.

$\mathrm{O}$ esgotamento da mineração no final do século XVIII, tanto em Mato Grosso como em Minas Gerais, fez com que algumas famílias procurassem novos lugares para viver. É nesse contexto, e a partir do fim da segunda década do século XIX, que começa a se destacar a localidade de Sant' Ana de Paranaíba.

Neste artigo, propomos uma análise do processo de ocupação dessa região, em que a escolha das unidades espaciais levou em conta a complexidade espacial, desmistificando a ideia de espaço enquanto palco para o acontecimento das relações humanas. $\mathrm{O}$ aprofundamento sobre a mecânica do exercício do poder patriarcal também foi alvo de nosso interesse, sendo compreendido pelo processo de transformação do espaço em território a partir da apropriação.

\section{A busca de terras por Barão de Antonina}

João da Silva Machado (1782-1875), barão de Antonina, buscou apropriar-se de grandes extensões de terras, com o apoio de
Joaquim Francisco Lopes, na localidade que ficaria conhecida como Sant' Ana de Paranaíba. Apesar de ter nascido e vivido boa parte de sua vida no Rio Grande do Sul e de ser de origem humilde, ele conquistou postos políticos de destaque (chegou à vice-presidente) na então província de São Paulo. Esses cargos, juntamente com seu conhecimento de tropeiro e negociante de gado, devem tê-lo atinado para a situação de "vazio" da região que estava na divisa entre a província de São Paulo, Goiás e Mato Grosso e que poderia ser propícia para a criação de gado.

Segundo Virgílio Corrêa Filho, as terras que o barão de Antonina pretendia estavam “entre o Paraná, Amambai, Ivinhema, Dourados, Serra de Maracaju, estendendo-se pelo Apa e outros afluentes do Paraguai" (1923, p. 23). Assim, ele contratou Joaquim Francisco Lopes para conhecer e tomar posse de terras em seu nome.

O barão nunca exerceu efetivo domínio sobre as vastíssimas áreas, abandonando-as pela incapacidade de provar serem todas de sua propriedade. Após a morte do barão, suas terras transformaram-se em objeto de demanda judicial, como mostram os processos movidos entre seus herdeiros e o estado de Mato Grosso. A tentativa de legalização das referidas terras foi contestada pelo governo do estado de Mato Grosso por meio do advogado Astolpho Vieira de Resende, que sustentou que as terras pretendidas não passavam de fraude.

Sobre esse processo, a historiadora Vilma Eliza Trindade de Saboya teceu algumas considerações em um artigo publicado na Revista Brasileira de História, em 1995, sob o título “A Lei de Terras (1850) e a política im- 
perial - seus reflexos na província de Mato Grosso". Segundo a autora:

É patente o conluio; é manifesto o artifício, fraudulento de que se valeram compradores, vendedores e inventariante [que requereu a execução da hipoteca, motivo do processo], para se apoderarem dessa vasta extensão territorial do domínio do Estado de Mato Grosso [sul de Mato Grosso: terras em Nioaque, Bela Vista e Ponta Porã], num processo de amigos e compadres, em que o Estado não fosse parte, e donde fosse excluído, para se facilitar a execução da empreitada (SABOYA, 1995, p. 130).

O exemplo da tentativa de regularização das terras pelos herdeiros do barão de Antonina demonstra claramente não só o uso da lei, mas também a sua burla, com o uso de documentos falsos para conseguir o registro de propriedade de glebas já famosas por terem outros proprietários (CORRÊA FILHO, 1923).

O processo dos Embargos de Mato Grosso, publicados em 1924 pelo advogado Astolpho Rezende, comprova a falsificação de posse do barão e acusa seu agente Joaquim Francisco Lopes de participar do procedimento ardiloso:

[...] arranjar algumas escrituras de terras em Mato Grosso, para fim de converter-se em grande proprietário de latifúndios naquela província [...] de posse dessas escrituras que eram na sua quase totalidade escritura de mão, o referido barão fez delas um simulacro de registro, perante o vigário da freguesia de Miranda (REZENDE, 1924, p. 35).

Apesar de pretender tomar posse de terras em Mato Grosso, o plano do barão de Antonina acabou não dando certo com o passar dos anos por falta de ocupação e uso da terra "conquistada". Porém, Joaquim Francisco Lopes aproveitou-se da situação e fez posse não só para o barão, mas também para si, sendo acompanhado de alguns outros homens que acabaram se fixando na região.

\section{Joaquim Francisco Lopes e suas explorações}

As derrotas de Joaquim Francisco Lopes é um texto que trata das expedições de conhecimento e exploração do sul do antigo Mato Grosso, patrocinadas pelo barão de Antonina. Esses relatórios foram publicados em 2007 pelo Instituto Histórico e Geográfico de Mato Grosso do Sul na Série Relatos Históricos - volume II. Campestrini (2007), organizador da obra, declara que a primeira das quatro derrotas foi escrita por Lopes, conhecido também como Sertanejo, e os outros relatórios foram escritos por João Henrique Elliot, um dos homens que compunham o grupo exploratório.

A primeira exploração (1829-1839) tinha como objetivo reconhecer o sertão de Sant'Ana de Paranaíba, abrir um caminho daquela povoação até o forte de Miranda e introduzir melhoramentos na estrada conhecida como Picadão (do Tabuado até Piracicaba). Logo no início do documento, que incumbe a entrada à Lopes, é sinalizado que ele deveria se dirigir à fazenda do delegado José Garcia Leal e requisitar a ele todo o auxílio necessário para a empreitada, como os camaradas (trabalhadores) e mantimentos.

Assim, podemos perceber a relação entre Joaquim Francisco Lopes e a família Garcia Leal, a qual se tornou um dos "grandes nomes" na ocupação de Sant'Ana de Paranaíba, que, à época, ficou conhecida também como "Sertão dos Garcia". E foi a partir da 
relação dessa família com algumas outras que acabou se formando uma pequena elite.

A segunda derrota durou de 1844 a 1847 e teve como propósito descobrir uma via de comunicação fluvial do Paraná ao Baixo Paraguai. Para isso, seguiu-se uma bandeira composta por dezenove pessoas, que se iniciou no Rio Verde e percorreu mais de duzentas léguas, conforme o itinerário. Durante o percurso, há o relato de terem matado uma onça pintada:

Matamos um tigre, que nos ia seguindo pela margem do rio [rio Samambaia]; era fêmea, e tinha três pequenos no ventre inteiramente perfeitos e já pintados; menciono esta circunstância porque parece me que raríssimas são as vezes que elas têm mais do que duas crias de um parto. Oito ou dez léguas acima da barra começa a aparecer muitos palmitos buriti; logo adiante o rio, pendendo para NO, afasta-se do Paraná, e a aparição de muitos cervos assegurava-nos que o campo não estava longe; daqui para cima ficava cada vez mais estreito e mais tortuoso o rio, e a corrente mais rápida (CAMPESTRINI, 2007, p. 76).

Nessa segunda derrota, a narrativa demonstra que o barão de Antonina recomendava para as pessoas que compunham a entrada não maltratarem os indígenas que encontrassem e que, algumas vezes, era necessário "presenteá-los" com ferramentas, roupas, barretes e miçangas, negligenciando as armas de fogo por medo de um contra-ataque. Nessa empreitada, foram encontrados indígenas de várias etnias: quiniquinaus e terenas, por exemplo.

A terceira derrota ocorreu durante os anos 1848 e 1849 e tinha o intuito de explorar e buscar a melhor via de comunicação entre a província de São Paulo (desde o Paraná) e a de Mato Grosso pelo baixo Paraguai. A expedição foi composta por nove pessoas e um intérprete, que, após desaguarem no Rio Ivinhema, intermediou a conversa com os índios caiuás, de nação guarani, contabilizados em torno de quatro mil. Esses indígenas cultivavam milho, mandioca, abóboras, batatas, amendoins, jucutupé, carás, tingas, fumo e algodão.

A quarta derrota foi curta - de agosto a novembro de 1857 -, e o propósito era explorar os rios Iguatemi, Amambaí e parte do Ivinhema, com os terrenos adjacentes. Essa expedição era para ser composta pelo comandante e o piloto,

[...] os camaradas para pilotos e proeiros das canoas, doze índios e quatro africanos para remeiros tirados das aldeias de S. Pedro de Alcântara do Jataí, e de N. S. do Loreto do Pirapó e mais oito praças da primeira linha, e um inferior para manter a ordem e servirem de proteção à expedição (CAMPESTRINI, 2007, p. 117).

Porém, houve problemas nessa composição: por rixa, um camarada assassinou o colega; então, dois outros camaradas acobertaram a fuga do criminoso; um camarada morreu afogado no Rio Tibagi e outro ficou doente. A entrada, que de início tinha oito camaradas, ficou reduzida a dois. Agravando-se ainda mais em Jataí, pois não conseguiram preencher a quantidade de doze indígenas, conforme o planejado, ficando com apenas sete.

De forma geral, os relatórios narram sobre a quantidade de homens nas comitivas; o uso de animais nas entradas, como cães veadeiros; o infortúnio de serem atacados por carrapatos e de terem sarna; as dificuldades em navegar pelos rios; como 
foram construídas as fazendas e as moradas; as doenças e epidemias que enfrentaram e os roteiros realizados nas expedições.

O documento também é interessante ao retratar a alimentação, como o caso de um bebê de quatro meses que, com a mãe doente, foi alimentado com mingau de raspa de mandioca, farinha de milho e mel. Além disso, há o relato de que indígenas da etnia caiapó faziam parte da comitiva juntamente com escravos negros.

Apesar de as Derrotas terem sido escritas como diários de viagem, que narravam os roteiros seguidos, falavam sobre a situação dos rios, etc., hoje, elas são uma fonte histórica, que nos faz refletir sobre esse movimento de entrada e exploração do interior brasileiro. Também podem ser uma grande referência para estudos da História Ambiental que busquem analisar a relação do "homem branco" com a natureza recém-descoberta.

Joaquim Francisco Lopes, apesar de ser um funcionário do barão de Antonina, utilizou-se de seu conhecimento e de sua exploração para tomar terras para si, e não somente para seu patrão. As entradas também possibilitaram a criação de vínculos sociais e de amizade com pessoas que também tinham interesse em se fixar na região. Joaquim Francisco Lopes nasceu em Minas Gerais, no ano de 1805 , e parece ter falecido em 1868, em uma colônia indígena em Mato Grosso, em uma situação de extrema pobreza.

João Henrique Elliot era estadunidense e chegou ao Brasil entre 1825 e 1826, por volta dos 16 anos de idade. Ele veio em uma embarcação comandada por seu tio, Jesse Duncan Elliot. Logo, ingressou na Armada Imperial como tenente para participar de uma ação contra a independência da região Cisplatina. ${ }^{1}$ Depois desse trabalho, Elliot voltou ao Rio de Janeiro, onde conheceu o barão de Antonina e concordou em participar de expedições exploratórias na província de Mato Grosso, como cartógrafo e geógrafo. Ele deixou importantes registros visuais e textuais sobre os indígenas, tendo convivido com eles até sua morte, que parece ter ocorrido em 1884.

\section{A posse de terra em documentos}

Em uma tabela de 1854, publicada na Revista do Instituto Histórico de Mato Grosso (1919) (CAMPESTRINI, 2007), consta a existência de 97 propriedades que estariam sujeitas ao pagamento do imposto territorial a partir daquela avaliação, mas não se sabe se realmente houve a cobrança do imposto e se ele foi pago. O que chama a atenção é o tamanho das propriedades, que varia de 828.240 hectares (da propriedade Campo Triste) a 1.139 hectares (da Bahusinho). Nessa tabela, há cinco fazendas das quais não se sabe a medição. Não é descrito no documento como foi feita a medição e nem quem foi o responsável.

No Arquivo do Tribunal de Justiça de Mato Grosso do Sul, foram encontrados vários documentos relativos às propriedades, como autos de posse e lançamentos de títulos de terras, no período compreendido entre 1838 e 1888, mas os documentos se silenciam quanto ao tamanho da posse, relatando, no máximo, seus limites territoriais.

Em 15 de dezembro de 1839, Antônio Aparecido dos Santos procurou o Juiz de Paz, Januário José de Souza, para registrar uma Portaria na qual a sua Majestade Real 
teria doado uma área de cinco sesmarias na província de São Paulo, porém, fazendo barra com o Rio Grande e o Rio Paranaíba, em frente à Ilha das Três Províncias de São Paulo e Mato Grosso, e a posse deveria se chamar "Cruis deta". Essa doação foi datada pelo imperador no dia 31 de outubro do mesmo ano. Não sabemos se foi verificada a idoneidade do documento, pois nada consta sobre isso, somente que Antônio apareceu com a doação que foi registrada e dada a posse. ${ }^{2}$

Em 29 de julho de 1846, foi feita a abertura e o termo de registro de uma sesmaria para José Ignácio da Silvera, que era natural de Uberaba, província de Minas Gerais, apesar da Lei de Sesmarias ter sido suspensa em 1822. A localidade da sesmaria parece ultrapassar a região que ficou conhecida por Sant'Ana de Paranaíba, mas o documento foi feito pelo escrivão de Sant'Ana de Paranaíba, à época, Manoel Pereira de Araujo. Assim é descrita a localização da sesmaria de Silvera:

[...] em tereeno Deisheto na Sertao do camopoam e cabeseras do Rio Pardo comescando as suas devisas da barra da agua vermelha com o Ribeirão do capim branco sobim por este assima capim branco athe a Lagoa das seasmesugas vertentes e sobindo nadita laga dos seamesugas em rumo as sabeceras do Ribeirão denominado Mata-mata e de sendo Ribeirão a baxo ate a barra do camapoham e sobindo camopoham assima 2 Leguas mais omenos athe frontreiar a ponta da [ilegível] e sobindo poresta assima e procurando a sobra da dita agua Vermelha e poresta abaxo athe onde teve principio tudo qnte. ${ }^{3}$

Podemos verificar que o documento não se refere a nenhum sistema de medição que diga, por exemplo, quantos hectares ou $\mathrm{km}^{2}$ a sesmaria possuía, só cita as divisas que são referidas por rio, lago e ribeirão, levando-nos a refletir sobre a importância da água no valor e na posse da propriedade. $\mathrm{O}$ documento menciona apenas quais seriam os limites da posse.

Sobre a falta de preocupação em demarcar terras no Brasil oitocentista, Chalhoub explica que:

Fazenda demarcada é propriedade finita, expansão dificultada; a indefinição dos limites da propriedade é aposta no futuro, esperança de usurpação do público e do alheio (1998, p. 12).

Ao estudar o interior do Rio de Janeiro, Márcia Motta infere que havia uma resistência em medir e demarcar as terras porque a limitação territorial se relacionava a " $[. .$.$] um limite do exercício de poder sobre$ vizinhos e posseiros e uma subordinação ao poder externo, representado pela Coroa" (1998, p. 39).

Além de não querer limitar seu poder, era interessante para o senhor não documentar os limites de sua posse, e isso pode ser visto nos inventários post mortem de Sant'Ana de Paranaíba, pois, neles, não são demarcados os limites das propriedades, somente em alguns documentos são citadas as divisas da posse, pois assim poder-se-ia aumentar a extensão de suas terras. Chalhoub (1998) atenta para os riscos de tal manobra, entre os quais, talvez, possam ser inseridas as brigas e as perdas de posse de terra.

\section{Os contratos de compra e venda}

Em 1838, houve um contrato de compra e venda entre o capitão José Garcial Leal e sua esposa, Anna Angelica de Freitas (ven- 
dedores), e Desiderio Rodrigues da Costa (comprador). O casal possuía uma sorte de terras que se compunham de capões de matos de cultura, campos e catandubas, sítios à margem do Rio Sant'Ana, com suas divisas:

Começando do dito Sant'Anna onde faz barra neste o córrego Lageado e por este veio d'agua acima ate a sua última cabeceira divisando com o capitão Jose Coelho de Souza, e daqui segue pelo espigão mestre acima ate circular a cabeceira do córrego da morado do mesmo oltogardo (José Garcia Leal), e daqui pelo espigão deste abaixo compreendendo o dito corrego ate o dito rio divisando com Jacinto Antonio Ferreira, e seguindo o rio Sant' Anna abaixo ate o dito Lageado onde começou esta divisa. ${ }^{4}$

No documento que os vendedores já tinham cedido e transpassado o domínio anteriormente à oficialização, Desiderio ficou responsável por pagar o valor de trezentos mil reis, "de que se passou credito pelo tempo de três annos a pagamentos iguais", e o pagamento do imposto, chamado sisa, ficaria a cargo dos vendedores. ${ }^{5}$

O tamanho da posse não é citado nos contratos de compra e venda de terras em Sant'Ana de Paranaíba. Em 1873, Gabriel Ferreira de Mello e sua esposa Victoria Maria de Jesus venderam uma parte de terra da fazenda Bonito para Manoel Garcia da Silveira pelo valor de um conto de réis. Essa parte compreendia o Pontal denominado Bonito, que tinha as seguintes divisas:

Comecando no pontal pelo lado direito serve de diviza o mesmo braço que divide a Fasenda do Bonito com a do Bebedouro, por esse braço ascima ate a ultima cabeceira pela agua maior, dividindo lá com a Fasenda da Velhacaria; isto é, por esse braço ate o primeiro braço que esgalha para a esquerda; partindo outra vez do referido Pontal, segue pelo meio d'agua do braço do Bonito, que vem da esquerda ate a sua ultima cabeceira, pela agua maior, d'ahi ao espigão mestre do rio das Pedras com o Bonito, e por esse espigão ascima até confrontar com as divisas da Fasenda Velhacaria. ${ }^{6}$

Em 1873, também foi registrada a escritura de compra e venda de uma morada de casa e quintal no Porto de Paranaíba. Os vendedores eram Isaias Joaquim Guimarães e sua mulher Anna Cezarina dos Santos e o comprador era Antonio José Teodoro. A morada de casas era térrea e coberta de telhas, com quintal cercado. $\mathrm{O}$ valor combinado foi de 340 mil réis, porém, não estavam inclusas as plantações e a chácara do lado direito. ${ }^{7}$

Esses documentos são exemplos da falta de interesse ou de cuidado em não colocar no papel a área ocupada e vendida, contudo, sabemos que isso era intencional e que pode ter sido motivo de várias contendas posteriores pela demarcação das propriedades. Também não podemos deixar de notar a importância da água para a fixação dessas pessoas na propriedade.

As expedições de exploração da região por Joaquim Francisco Lopes levantaram o conhecimento da região, que instigou a busca pela sua posse e ocupação não só do barão de Antonina, mas de famílias que tinham contato com Lopes, já que a região era banhada por muitos rios e córregos.

A importância de se ter uma propriedade com algum recurso hídrico se dá pelo fato de a água ser uma substância vital para a sobrevivência das pessoas e dos animais, além de ser imprescindível para o uso cotidiano, como tomar banho, cozinhar, lavar roupa, regar as plantas, etc. Além disso, o 
bioma cerrado, existente na região, tornava a localidade propícia para a criação de gado.

De forma geral, encontramos a posse de terra por entrantes em três tipos de documentos: a doação de sesmarias (realizadas mesmo após o fim desse regime), a declaração em inventários post mortem e os contratos de compra e venda. Somente a posse de terra por doação de sesmarias é que podemos destacar, com uma doação da terra pelo Estado, porém, sem pensar em uma ocupação legal efetiva, pois não havia mais vigência desse tipo de posse. A exceção é a Portaria de doação de terra conseguida por Antônio Aparecido dos Santos, única que parece válida nesse quesito.

A declaração nos inventários post mortem e os contratos de compra e venda não fazem relação ou citação de como ocorreu a primeira posse, ou seja, como conseguiram a posse na passagem do antigo proprietário, deixando em aberto para indagações da legalidade e da legitimidade da propriedade.

\section{A produção de novos territórios e 0 exercício do poder patriarcal}

Ao nos debruçarmos sobre a prática da apropriação de terras na região de Sant'Ana de Paranaíba, ocorrida no século XIX, destacam-se pistas que sugerem o exercício do poder por parte de figuras que detinham certo prestígio na época. A análise dos documentos (inventários e contratos de compra e venda de propriedades rurais) nos levou a investigar com mais cuidado o processo de ocupação espacial, conferindo, então, especial atenção aos conceitos geográficos de espaço e território, cujo entendimento permite avanços teóricos sobre o exercício do poder patriarcal.

O espaço constitui-se como conceito-chave da geografia e é, até os dias de hoje, amplamente estudado pelos geógrafos. De acordo com Moraes (2002), há três possibilidades para o seu entendimento: 1) o espaço enquanto categoria de estudo geográfico, ou seja, enquanto ferramenta analítica para as construções intelectuais; 2) o espaço apreendido como atributo dos seres, nesse sentido, nada existiria sem ocupar um determinado espaço - essa forma de entender o espaço o coloca como palco das relações sociais ou naturais; 3) o espaço como ser específico do real, com características e com uma dinâmica própria. Este estudo da geografia enfatiza a busca da lógica da distribuição e da localização dos fenômenos, sendo, então, a essência da dimensão espacial.

De acordo com Carlos, o espaço articula duas dimensões, a da localização e a que dá conteúdo a essa localização, que a qualifica e singulariza. Esse conteúdo é determinado pelas relações sociais que aí se estabelecem: "o que confere ao espaço a característica de produto social e histórico" (1999, p. 175).

Não obstante, consideramos que o espaço não é apenas uma condição da evolução social, ou ainda uma configuração da paisagem, mas, também, sem dúvida, um fator da evolução social, o espaço deve ser considerado como uma instância da sociedade, assim como uma instância econômica e cultural-ideológica, isso significa que a essência do espaço é social. Ele não pode ser formado apenas pelas coisas, os objetos geográficos, naturais e artificiais, cujo conjunto nos dá a natureza. "O espaço é tudo isso mais a socie- 
dade: cada fração da natureza abriga uma fração da sociedade atual" (SANTOS, 1992, p. 1).

Entre as perspectivas da análise espacial, que leva em conta toda a sua complexidade, nos chama a atenção a elaborada por Henri Lefebvre, em seu livro The Production of Space (1991), justamente por identificar aquilo que o autor coloca como tríade espacial, compreendendo o espaço percebido (relacionado às práticas espaciais), o espaço concebido, (associado às representações do espaço) e o espaço vivido (ligado ao uso que se dá no espaço).

Retomando a análise feita a partir dos contratos de compra e venda das propriedades rurais e dos inventários post mortem em Sant'Ana de Paranaíba, podemos afirmar, com muita segurança, que os atributos espaciais constituíram-se em fatores muito importantes para a escolha das unidades espaciais apropriadas. É importante ressaltar que a região estudada é predominantemente caracterizada pelo cerrado brasileiro, sendo uma área composta por vegetação rasteira (gramíneas) e árvores de porte médio. Quanto ao clima, observa-se uma sazonalidade nos regimes pluviométricos (chuvoso no verão e seco no inverno).

Considerando que a principal atividade econômica na região era a pecuária extensiva, não é difícil presumir que, para se obter maiores condições para a ampliação dos lucros, eram necessárias grandes áreas de pastagem (garantidas pela vegetação característica do cerrado), assim como recursos hídricos (rios e lagos), uma vez que os períodos de estiagem trazem dificuldades para a engorda do rebanho.
Reconhecemos que o espaço não é um simples palco no qual as relações humanas simplesmente acontecem, corroborando o pressuposto apresentado por Corrêa (1993), de que o espaço é, ao mesmo tempo, condição e condicionante da reprodução da humanidade. No entanto, para compreender a extensão e a mecânica do exercício do poder patriarcal, é preciso investigar o processo que marca a transformação do espaço em territórios rurais na região de Sant'Ana de Paranaíba.

Apoiados nas contribuições de Raffestin, entendemos que "o espaço e o território não são equivalentes, é necessário entender que o espaço é anterior ao território" (1993, p. 143). O território se forma a partir do espaço, é o resultado de uma ação conduzida por um ator sintagmático (agente responsável pela apropriação do espaço e, consequentemente, pelas manifestações de relação de poder nesse território). Ao se apropriar de um espaço concreto ou abstrato, esse agente territorializa o espaço.

Não por acaso, na concepção ratzeliana, o território define-se pela propriedade, isto é, representa uma parcela do espaço terrestre identificada pela posse. Ratzel, apesar de não fazer uma distinção entre a questão do território e a do espaço, já apontava um fator essencial para que o façamos, a apropriação (ANDRADE, 1995).

De acordo com Soja (1993), o espaço é compreendido como produto social, que é organizado no sentido político e ideológico, expressando relações sociais. Com isso, fica claro que nem todos os espaços sociais são território, mas apenas aqueles apropriados. Então, percebe-se que o território não pode ser passivo, em sua essência, ele é tido pela 
apropriação, fator que está carregado de poder, "o território é um instrumento de exercício do poder" (MORAES, 2002, p. 20). De modo semelhante, Foucault argumenta que o território é, sem dúvida, uma "noção geográfica, mas é antes de tudo uma noção jurídico-política: aquilo que é controlado por um certo tipo de poder" (2007, p. 157).

As relações de poder ainda foram estudadas por outra metodologia, assim como evidencia Raffestin (1993), que descreveu o poder por sua sintaxe linguística, caracterizando a palavra por suas maiúsculas e minúsculas. Marcado pela letra inicial maiúscula, o termo equipara-se "a um conjunto de instituições e de aparelhos que garantem a sujeição de cidadãos a um Estado determinado" (LEFEBVRE, 1972 apud RAFFESTIN, 1993 , p. 51). Nesse caso, o Poder, com a letra inicial maiúscula, postula a soberania do Estado, da nação, que é fundamentada por leis e regimentos. Assim, o poder apresenta-se visível a todos, familiar, mais marcante e também mais habitual à familiaridade de seu nome, movido enquanto sinônimo de Estado.

Seria o antigo sistema dos filósofos do século XVIII, que se articula em torno do poder como direito garantido que se cede, constitutivo da soberania, tendo o contrato como matriz do poder político. O poder que corre o risco, quando se excede, quando rompe os termos do contrato, se torna opressivo. Poder-contrato, para o qual a opressão seria a ultrapassagem de um limite (FOUCAULT, 2007, p. 177).

Quanto ao poder, nome comum, como diz Raffestin (1993), com letra minúscula, esconde-se atrás do Poder (nome próprio). Esconde-se melhor quando sua presença está em todos os lugares. Está presente em cada relação, na curva de cada ação: insidioso, aproveita-se de todas as fissuras sociais para infiltrar-se até o coração do homem. $\mathrm{O}$ autor analisa o poder por sua funcionalidade econômica, no sentido em que teria como papel, essencialmente, manter as relações de produção e reproduzir uma dominação de classes que o desenvolvimento e uma modalidade própria das forças produtivas tornaram possível. Com isso, o poder político não seria mais analisado pelo modelo "contrato-opressão", mas seguiria o esquema guerra-repressão, que não se basearia mais pelo abuso, "ao contrário, o simples efeito e a simples continuação de uma relação de dominação" (FOUCAULT, 2007, p. 177).

A ambigüidade se encontra aí, portanto, uma vez que há o "Poder" e o "poder". Mas o primeiro é mais fácil de cercar porque se manifesta por intermédio dos aparelhos complexos que encerram o território, controlam a população e dominam os recursos. É o poder visível, maciço, identificável. [...] Porém o mais perigoso é aquele que não se vê, ou que não se vê mas porque acreditou tê-lo derrotado, condenando-o a prisão domiciliar. [...] Desde então, o poder torna-se perene, pois não é mais visível, é consubstancial com todas as relações (RAFFESTIN, 1993, p. 52).

Em torno dessa discussão do poder, é por meio de sua mecânica que poderemos verdadeiramente definir sua atuação dentro de um sistema territorial. Foucault indaga que "o poder é o que reprime a natureza, os indivíduos, os instintos, uma classe" (2007, p. 175). Nesse sentido, constatamos que a mecânica do poder é dada pela repressão, que sua existência só se dá por sua ação, 
como também pela afirmação de que o poder não é principalmente manutenção e reprodução das relações econômicas, mas, acima de tudo, uma relação de força.

O modo como foi elaborada a delimitação das fazendas em Sant'Ana de Paranaíba é um bom exemplo do exercício do poder nesses novos territórios. Os documentos indicam como limites algum marco geográfico, como rios ou formas de relevo, dando uma ideia vaga dos limites das propriedades rurais, tornando as fronteiras territoriais móveis, podendo aumentar ou diminuir sua extensão territorial, de acordo com o resultado das tensões decorrentes do exercício do poder de seus proprietários.

Sendo assim, os territórios se formam em determinado espaço, no qual se realizam relações de poder. Essas relações são limitadas espacialmente, tanto no sentido da dominação quanto da resistência do dominado.

Assim, território implica a existência de fronteira, mesmo que esta não seja demarcada e exista apenas como uma referência rarefeita e/ou imaginária (SILVA, 2002, p. 21).

Considerando que a produção e a reprodução da vida são tecidas por relações, tanto do homem com o meio quanto do homem com o próprio homem, consideramos que a territorialidade pode ser definida como "um conjunto de relações que se origina num sistema tridimensional sociedade-espaço-tempo em vias de atingir a maior autonomia possível, compatível com os recursos do sistema". Cada sistema territorial segrega sua própria territorialidade, que os indivíduos e as sociedades vivem. A territorialidade se manifesta em todas as escalas espaciais e sociais, ela é consubstancial a todas as relações e é possível dizer que, "de certa forma, é a face vivida da face do poder" (RAFFESTIN, 1993, p. 161). O que percebemos é que a territorialidade é uma representação das formas de apropriação territorial, as quais expressam as formas de poder em seus mais variados graus, provenientes do tipo de apropriação.

\section{Consideraçōes finais}

Neste artigo, buscamos compreender o processo de ocupação territorial da região de Sant'Ana de Paranaíba, iniciado no século XIX, com a análise a partir de três instrumentos de acesso às propriedades rurais, a saber: a doação de terras, das quais uma foi feita pelo próprio Imperador do Brasil por meio de uma portaria publicada em outubro de 1839, os processos de inventários post mortem e os contratos de compra e venda de terras.

A análise dos documentos evidenciou algumas lacunas do processo de ocupação territorial, como as ocupações ilegais de terras, que, como identificamos na bibliografia consultada, é um marco característico e histórico da ocupação do território brasileiro. Tal procedimento permite compreender a intensa concentração de terras na região estudada.

Consideramos importante ressaltar que o processo de ocupação dessa região não se deu apenas por instrumentação jurídica, mas também por luta e desapropriação. A ideia defendida pelos entrantes em Sant'Ana de Paranaíba, de que a região encontrava-se inabitada, compreendida a partir de um contexto de "vazio territorial", não passou de um discurso utilizado para a legitimação da apropriação, desconsiderando a 
imensa população indígena que nela vivia e se reproduzia espacialmente.

Quanto à análise espacial, reconhecemos que as características espaciais foram consideradas no processo de escolha das propriedades, sendo as áreas localizadas próximas aos recursos hídricos amplamente procuradas, o que demonstra que o espaço não é apenas o local onde as interações sociais ocorrem, é mais do que isso. Ele é determinante e possibilitador de novas relações.

Por fim, ao ajustar nossas lentes de análise ao processo de transformação do espaço em território, conseguimos examinar com mais clareza o exercício do poder, sobretudo do poder patriarcal, que, como já mencionamos ao longo deste artigo, articula-se em duas frentes: a do Poder (com p maiúsculo) legitimado pelos instrumentos jurídicos e a do poder (com p minúsculo), indicioso, que se manifesta em meio à obscuridade instrumentalizada pelo exercício da territorialidade dos proprietários das terras, pela ilegalidade das apropriações, pelo extermínio e pela expulsão da população indígena, pela inexatidão do tamanho das propriedades rurais e pela porosidade conferida aos limites territoriais das fazendas.

\section{Abstract}

This article aims to discuss the land ownership in Sant'Ana de Paranaíba in the nineteenth century, from post mortem inventories and contract of buy and sell; existing documents in the Archive of Justice Court of Mato Grosso do Sul situated in Campo Grande. The text is linked to the geographical concepts of space and territory to better understand the occupation of this locality. In the spatial analysis we recognize that the spatial characteristics were taken into account, in the choice of the properties, and the areas located close to water resources, demonstrating that space is not only the place where social interactions occur, it is more than that, it is the same time are determinant and enabler of new relationships.

Keywords: Spatial analysis. Occupation. Sant' Ana Paranaíba.

\section{Resumen}

Este artículo tiene como objetivo discutir la propiedad de la tierra en Sant'Ana de Paranaíba en el siglo XIX, a partir de los inventarios post mortem y los acuerdos de compra y venta; documentos existentes en el Archivo del Tribunal de Justicia de Mato Grosso do Sul con sede en Campo Grande. El texto está vinculado a los conceptos geográficos del espacio y del territorio para comprender mejor la ocupación de esta localidad. En el análisis espacial reconocemos que las características espaciales se han tenido en cuenta en el proceso de selección de las propiedades, siendo que las zonas se encuentran cerca de los recursos hídricos, lo que demuestra que el espacio no es sólo el lugar donde se producen las interacciones sociales, es más que eso, es determinante y a la vez facilitador de nuevas relaciones.

Palabras clave: Análisis espacial. Ocupación. Sant'Ana Paranaíba. 


\section{Notas}

1 Arquivo Público do Paraná. Catálogo seletivo de documentos referentes aos indígenas no Paraná provincial: 1853-1870. Curitiba: Imprensa Oficial, 2007. p. 23

2 Arquivo do Tribunal de Justiça de Mato Grosso do Sul. Livro de notas n ${ }^{\circ}$. 1. Paranaíba 1838-1859. Fichário 1. Gaveta 2. Pasta 158. Folha 09 e 09 (verso).

3 Arquivo do Tribunal de Justiça de Mato Grosso do Sul. Livro de notas n ${ }^{\circ}$. 1. Paranaíba 1838-1859. Fichário 1. Gaveta 2. Pasta 158. Folha 40.

4 Arquivo do Tribunal de Justiça de Mato Grosso do Sul. Livro de notas $n^{\circ}$. 1. Paranaíba 1838-1859. Fichário 1. Gaveta 2. Pasta 158. Folha 05 e 05 (verso).

5 Arquivo do Tribunal de Justiça de Mato Grosso do Sul. Livro de notas $n^{\circ}$. 1. Paranaíba 1838-1859. Fichário 1. Gaveta 2. Pasta 158. Folha 05 e 05 (verso).

6 Arquivo do Tribunal de Justiça de Mato Grosso do Sul. Livro de notas $\mathrm{n}^{\circ}$. 15. Paranaíba 18721873. Fichário 1. Gaveta 2. Pasta 161. Folha 03 (verso) e folha 04.

7 Arquivo do Tribunal de Justiça de Mato Grosso do Sul. Livro de notas $n^{\circ}$. 15. Paranaíba 1872-1873. Fichário 1. Gaveta 2. Pasta 161. folha 04 (verso).

\section{Referências}

ANDRADE, Manuel Correia de. A questão do território. In: A questão do território no Brasil. São Paulo: Hucitec, 1995. p. 19-28.

CAMPESTRINI, Hildebrando (Org.). As derrotas de Joaquim Francisco Lopes. Campo Grande: Instituto Histórico e Geográfico de Mato Grosso do Sul, 2007. (Série Relatos Históricos, v. II).

CARLOS, Ana Fani Alessandre. O consumo do espaço. In: . (Org.). Novos caminhos da geografia. São Paulo: Contexto, 1999. p. 173-186.

CHALHOUB, Sidney. Prefácio. In: MOTTA, Márcia Maria Menendes. Nas fronteiras do poder: conflito de terra e direito à terra no Brasil do século XIX. Rio de Janeiro: Vício de leitura; Arquivo Público do Estado do Rio de Janeiro, 1998. p. 11-12.

CORRÊA, Roberto Lobato. O espaço urbano. 2. ed. São Paulo: Ática, 1993.
CORRÊA FILHO, Virgílio. Questões de terras. São Paulo: Secção de Obras O Estado de São Paulo, 1923.

FOUCAULT, Michel. Microfísica do poder. 23. ed. Rio de Janeiro: Graal, 2007.

LEFEBVRE, Henri. The production of space. Oxford: Blackwell Publishing, 1991.

MORAES, Antonio Carlos Robert. Geografia: pequena história crítica. São Paulo: Hucitec, 2002.

MOTTA, Márcia Maria Menendes. Nas fronteiras do poder: conflito de terra e direito à terra no Brasil do século XIX. Rio de Janeiro: Vício de leitura; Arquivo Público do Estado do Rio de Janeiro, 1998.

RAFFESTIN, Claude. Por uma geografia do poder. São Paulo: Ática, 1993.

REZENDE, Astolpho. O estado de Mato Grosso $e$ as supostas terras do barão de Antonina. Rio de Janeiro: Papelaria St ${ }^{\mathrm{a}}$ Helena - S. Monteiro \& Cia Ltda, 1924.

SABOYA, Vilma Eliza Trindade de. A Lei de Terras (1850) e a política imperial - seus reflexos na Província de Mato Grosso. Revista Brasileira de História: Historiografia, propostas e práticas, São Paulo: Contexto, v. 15, n. 30, p. 115-136, 1995.

SANTOS, Milton. Espaço e método. 3. ed. São Paulo: Nobel, 1992.

SILVA, Jan Carlos da. O conceito de território na geografia e a territorialidade da prostituição. In: RIBEIRO, Miguel Ângelo. Território e prostituição na metrópole carioca. Rio de Janeiro: Ecomuseu Fluminense, 2002. p. 16-56.

SOJA, Edward W. Geografias pós-modernas: a reafirmação do espaço na teoria social. Rio de Janeiro: Zahar, 1993. 